NASA Technical Memorandum 101728

\title{
Integrated Flight-Propulsion Control Concepts for Supersonic Transport Airplanes
}

Frank W. Burcham, Jr., Glenn B. Gilyard, and Paul A. Gelhausen

(NASA-TM-101720) INTEGRATED

FLIOHT-PRCPULSION CONTROL CONCEPTS FOR

SUPERSUNIC TRANSPORT AIDPLANES (NASA)
N91-13460

CSCL OIC
Unclas

0319221

November 1990

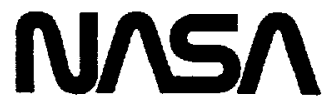

National Aeronautics and

Space Administration 


\section{Integrated Flight-Propulsion Control Concepts for Supersonic Transport Airplanes}

Frank W. Burcham, Jr. and Glenn B. Gilyard

NASA Ames Research Center, Dryden Flight Research Facility, Edwards, California

Paul A. Gelhausen

Ames Research Center, Moffett Field, California

\section{N/Sก}

National Aeronautics and

Space Administration

Ames Research Center

Dryden Flight Research Facility

Edwards, California 93523-0273 


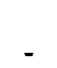

$-\quad$ I $=\quad$<smiles>[3H]I</smiles> 


\section{Integrated Flight-Propulsion Control Concepts for Supersonic Transport Airplanes}

Frank W. Burcham, Jr. and Glenn B. Gllyard NASA Ames-Dryden, Edwards, CA

Paul A. Gelhausen NASA Ames Research Center, Moffett Field, CA

\begin{abstract}
Integration of propulsion and flight-control systems will provide significant performance improvements for supersonic transport airplanes. Increased engine thrust and reduced fuel consumption can be obtained by controlling engine stall margin as a function of flight and engine operating conditions. Improved inlet pressure recovery and decreased inlet drag can result from inlet control system integration. Using propulsion system forces and moments to augment the flightcontrol system and airplane stability can reduce the flight-control surface and tail size, weight, and drag. Special control modes may also be desirable for minimizing community noise and for emergency procedures. The overall impact of integrated controls on the takeoff gross weight for a generic high speed civil transport is presented.
\end{abstract}

\section{NOMENCLATURE}

ACSYNT aircraft synthesis

ADECS adaptive engine control system

A8 convergent nozzle area

A9 divergent nozzle area

CG center of gravity

\begin{tabular}{|c|c|}
\hline EPR & engine pressure ratio \\
\hline FCS & flight-control system \\
\hline FNP & net propulsive force, lb \\
\hline HIDEC & $\begin{array}{l}\text { highly integrated digital } \\
\text { electronic control }\end{array}$ \\
\hline HSCT & high-speed civil transport \\
\hline$M$ & Mach number \\
\hline PSC & performance-seeking control \\
\hline SFC & specific fuel consumption \\
\hline TOGW & takeoff gross weight, lb \\
\hline$W A$ & airflow \\
\hline$\alpha$ & angle of attack \\
\hline$\beta$ & angle of sideslip \\
\hline 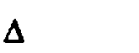 & change in parameter \\
\hline
\end{tabular}

INTRODUCTION

Interactions between the propulsion and flightcontrol systems (FCSs) of an airplane become stronger as the cruise Mach number increases. Minimizing unfavorable interactions and maximizing favorable interactions is a challenging task for control integration. Supersonic transport airplanes, with extended periods of cruise flight at 
Mach numbers in excess of 2.0, will have strong propulsion system-airframe interactions. In addition, there will be requirements to minimize community noise during takeoff and landing, minimize or eliminate sonic boom, and minimize emissions. These characteristics make the use of integrated propulsion-flight-control systems very beneficial.

NASA has conducted extensive flight studies of propulsion-flight-control integration (1)* both for the YF-12/SR-71 airplanes, which have a cruise Mach number in excess of $3,(2,3)$ and for the NASA F-15 highly integrated digital electronic control (HIDEC) airplane (4). Design methods for integrated control (5) have been developed and integrated airframe-propulsion system architecture studies have been conducted $(6,7)$. In addition, an adaptive optimization technique called performance-seeking control (PSC) has been studied $(8,9)$.

NASA is currently involved in the High-Speed Research Program. This program will determine the feasibility of developing an economical and environmentally acceptable high-speed civil transport (HSCT). Incorporation of integrated controls is one of the technologies being investigated. It is believed that control integration can improve performance, reduce environmental impact, and improve safety. When considered early in the design phase, control integration can result in a lighter, lower-drag, safer, and less expensive airplane. A design synthesis code $(10,11)$ has been used to assess the effects of the control integration

This paper will present some preliminary thoughts on the control requirements for a supersonic transport, identify the key control integration issues, and present some potentially beneficial integrated control modes, both for normal operation and for emergencies. Results of pertinent integrated control modes currently being tested are presented, and estimates of benefits for a HSCT are made. The overall effect of these benefits is assessed for a generic HSCT in terms of reduction in takeoff gross weight (TOGW) for a fixed range and payload.

- Numbers in parentheses designate references at end of paper.

\section{BACKGROUND}

The United States supersonic transport design of the early 1970 s had a limited experience base in propulsion-flight-control integration. Flight experience with the XB-70 and YF-12 airplanes had identified problems but few solutions. The NASA flight-research program on the YF-12 airplane documented the propulsion-flightcontrol system interactions, showing that, at Mach 3, forces and moments generated by the mixed compression inlet were similar to those of the flight-control system. Inlet unstarts, which occurred frequently, were violent and required significant control authority to maintain control. In addition, atmospheric temperature gradients were encountered which made it impossible to hold altitude and speed within the limits expected for subsonic flight.

After years of control system analysis, simulation, and flight research, these problems were solved. The cooperative control system, (1) implemented on the NASA YF-12C airplane, integrated the airdata, autopilot, autothrottle, inlet, and navigation functions. The system improved flightpath control by a factor of 10 , eliminated inlet unstarts, and provided inlet performance improvements that resulted in a 7-percent increase in range. This concept was implemented on the SR-71 fleet.

More recently, NASA, in conjunction with the USAF, McDonnell Douglas, and Pratt \& Whitney, has conducted integrated flight-propulsion control research on an F-15 HIDEC airplane. Initially, an active engine stall margin control mode was developed and tested. Excess engine stall margin was traded for thrust at times when the full stall margin was not needed. Specific fuel consumption (SFC) reductions were also obtained at constant thrust. Later, another active control mode was tested in which stall margin was traded for lower engine turbine temperature, thus extending engine life.

Integrated trajectory guidance experiments were also conducted, in which the flightpath and throttle commands were generated in an onboard computer. Minimum time, minimum fuel, or mini- 
mum fuel to arrive at a specified time modes were all investigated.

An inlet integration mode was also tested (12). Flight-control and engine parameters were supplied to an algorithm that trimmed the positions of the inlet ramps, resulting in improved performance.

A PSC system has recently been implemented which performs an onboard engine parameter identification, updates system models, and then optimizes the engines, inlets, and nozzles in near real time $(1,9)$.

\section{HIGH-SPEED CIVIL TRANSPORT DESCRIPTION}

A conceptual design of an HSCT is shown in Figure 1. The HSCT features a long slender fuselage, a large sharply-swept double delta wing, and underwing nacelles. This HSCT is 293-ft long and has a wingspan of $136 \mathrm{ft}$. The airplane will carry approximately 250 passengers over a range of approximately 5000 to 6000 nautical miles at cruise Mach number between 2.2 and 3.2. The takeoff gross weight (TOGW) will be approximately $650,000 \mathrm{lb}$; approximately 55 percent willbe fuel.

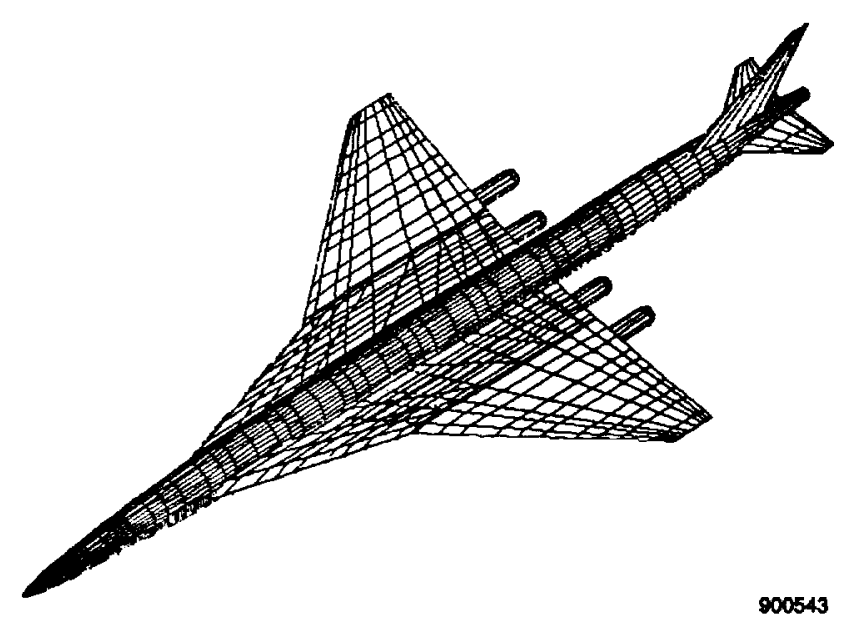

Figure 1. Generic high-speed civil transport.

\section{PROPULSION SYSTEM}

The propulsion system will likely consist of four inlet-engine-nozzle units mounted in underwing nacelles. Typically, the propulsion system weight will be approximately 18 percent of theempty weight.

INLET - Each engine will be fed by a variable geometry inlet; an external compression inlet may be practical for cruise Mach numbers up to 2.2. At higher Mach numbers, a mixed compression inlet will likely be required. Variable-geometry compression surfaces will be required to achieve high performance over the Mach range. Bypass doors will be provided to match inlet capture to engine demand. Boundary-layer bleed will be required to achieve high-inlet pressure recovery and low distortion.

Inlet Control - Control of the inlet will be a challenging and critical task for an HSCT. Inlet stability requires operating margins away from the optimum position, but these margins will reduce performance. Therefore, it is critical to operate with the minimum acceptable margin. Integration is a powerful method of minimizing these inlet operating margins. The inlet control system, either for an external compression or mixed compression inlet, will be a multichannel digital system with data bus communication to other systems.

External Compression Inlet - External compression inlets are less sensitive than mixed compression inlets because there is no unstart potential. However, a complex system is still required to position the compression surfaces and the bypass doors as a function of flight conditions and engine demand to achieve maximum performance.

Mixed Compression Inlet - A mixed compression inlet can achieve higher performance, but will have a much more complex control system because the inlet must be started (the terminal shock wave moved to an internal position downstream of the throat) and prevented from unstarting. Extensive studies of the mixed compression inlet of the YF-12/SR-71 airplane have been conducted, and have shown that high performance may be achieved without a significant incidence of inlet unstart (1). 
ENGINE - The HSCT engine design is still being studied, but will likely be a low pressure ratio engine in the $60,000-$ to $70,000-1 b$ thrust class. Engine cycles being considered include turbojets, turbofans, variable cycle engines, and turbine bypass engines. Afterburning may also be considered. There will be extensive variable geometry to achieve high performance over the wide operating range of an HSCT.

Engine Control - The HSCT engines will be complex and will require a carefully designed control system. A full-authority digital control system will be used to control the many engine variables. It is likely that each engine will have its own engine mounted control, although some studies have addressed the practicality of a remotely mounted centralized engine control system. The engine control will be interfaced through a data bus to other systems on the HSCT.

EXHAUST NOZZLE - Each engine will be equipped with a variable exhaust nozzle. The nozzle will provide convergent section throat area control for the engine, and divergent section control for supersonic cruise. Noise suppression will be provided for takeoff, and will probably require variable geometry.

Thrust vectoring capability could enhance performance for the HSCT. Low-speed control authority could be increased, and flight-control surfaces could be trimmed to the minimum drag position. The same capability could be used for moment generation and surface trimming at other flight conditions. This capability is not usually considered for an HSCT design, but a simple lightweight vectoring system might permit smaller and lighter tails and control surfaces, and improved performance.

Nozzle Control - The nozzle on the HSCT will require accurate control to maximize performance at cruise, and minimize noise at takeoff. The convergent nozzle area $(A 8)$ will be variable for engine control. The secondary nozzle area $(A 9)$ will be controlled to provide proper expansion as Mach number increases. Takeoff noise control will likely require additional nozzle variable ge- ornetry which will need to be positioned in concert with engine variables. If thrust vectoring should be available, it, too, will be controlled in an integrated manner with the rest of the nozzle control and the other propulsion and flight controls.

\section{FLIGHT CONTROLS}

The flight-control system will be a key element in the HSCT. There will most likely be a single vertical tail with a rudder. Roll control will be provided by ailerons or elevons. For pitch control, some configurations have separate horizontal tails, while others use the elevons on the wing for pitch control. There will possibly be highlift devices on wing leading edges in addition to trailing-edge flaps. Some designs have employed canards for additional pitch control. In some designs, multiple pitch control surfaces may be used, with control surface blending used.

FLIGHT CONTROL SYSTEM - A multichannel digital flight-control system is planned for the HSCT. The control and augmentation functions will be conventional; however, the HSCT configuration place a major emphasis on minimization of surface deflections to minimize total vehicle drag. The static stability of the aircraft will be driven by performance factors commensurate with the ability to control potential instabilities both longitudinally and lateral-directionally.

\section{HIGH SPEED CIVIL TRANSPORT SYSTEMS FOR INTEGRATION}

There will be many systems on a typical HSCT that will benefit from integration. In addition to the previously discussed propulsion and flight-control systems, there are other systems that need to be included in the overall integration scheme.

AIRDATA - Airdata provides important information to the cockpit, flight-control system, navigation system, and propulsion system. A nose mounted airdata system will be as much as 200 $\mathrm{ft}$ upstream of the inlets, and may be able to provide advance warning of atmospheric transients that can be used by the inlet control system to 
bias operation to higher stability. Use of a laser airdata system that looks ahead of the alrplane would provide longer warning times.

TRAJECTORY-NAVIGATION - An HSCT will have new requirements for trajectory control and navigation. Noise on takeoff will be controlled by a combination of flightpath, throttle, and noise suppressor. Climb will consume a significant percentage of fuel, and needs to be done at optimum conditions in terms of flightpath and throttle setting. Fuel consumption at cruise conditions can be significantly affected by atmospheric conditions. Sonic boom considerations may also require careful flightpath control. Fuel consumption at subsonic loiter will be high; therefore flightpath, throttle control, and aerodynamic surface positions should be managed to minimize drag. The trajectory should also be optimized with respect to air traffic control requirements. Finally, approach noise constraints may again require integrated control of throttle and flightpath. The ability to compute an optimal flightpath and throttle setting in real time as requirements change will provide significant benefits.
CENTER-OF-GRAVITY CONTROL - Centerof-gravity control will likely be provided by shifting fuel. The longitudinal CG will be controlled to achieve the desired degree of static stability, and lateral control may also be provided to minimize lateral control deflections. Fuel transfer systems are usually slow in response; therefore stability trades must consider potential unusual operations that may result from failures.

INTEGRATION ARCHITECTURE - The architecture for implementing the control systems for an HSCT will be studied for the next several years. To facilitate the integration of the various systems, yet keep the hardware and software development and verification and validation manageable, great care will have to be taken early in the design phase.

An overview of a potential integration hierarchy is shown in Figure 2. Individual control systems may be provided for the inlet, engine, and nozzle. An integrated nacelle control system for each propulsion system could be developed, followed by an overall propulsion system integrated control. The next level might be the integrated

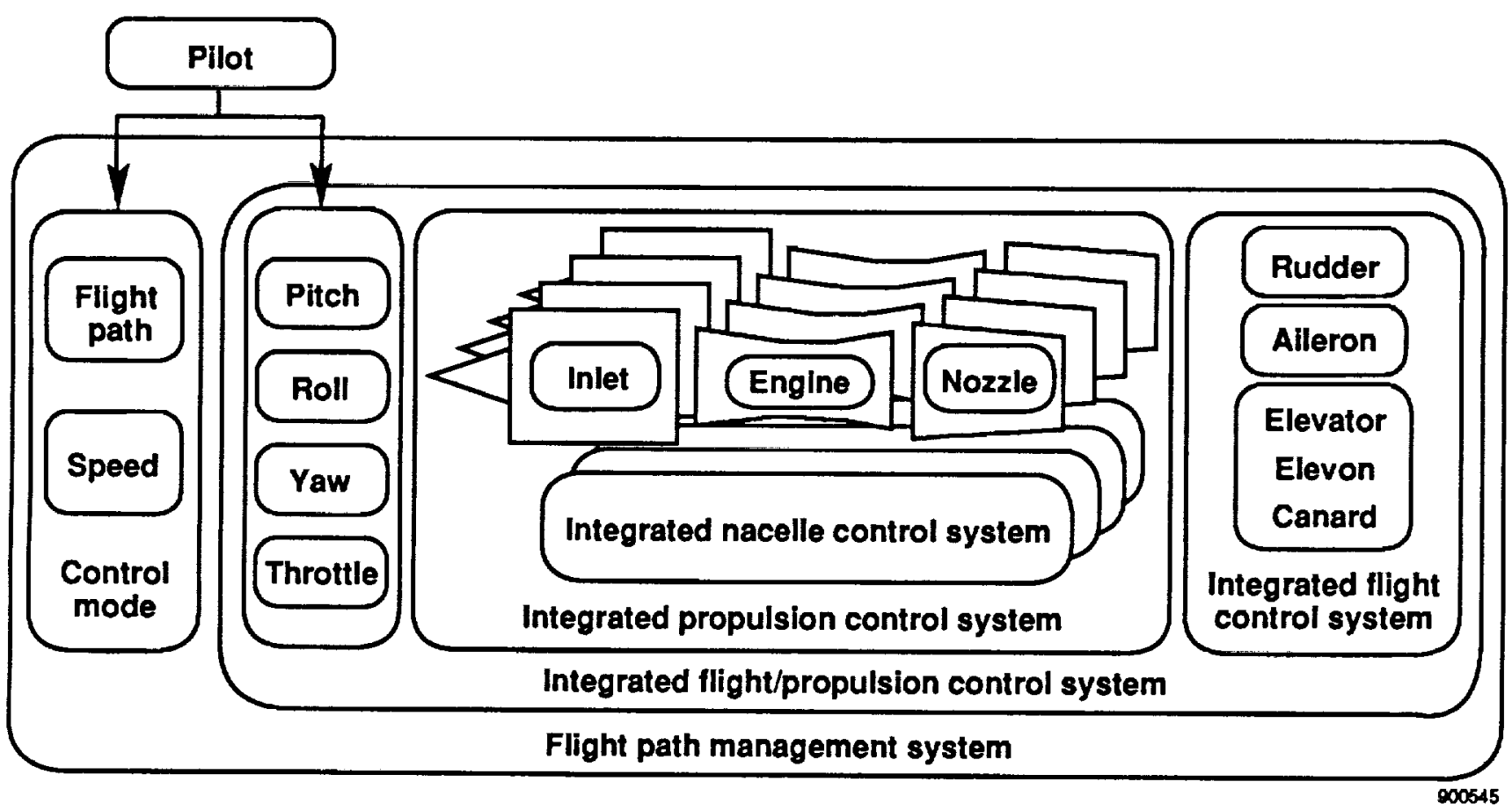

Figure 2. High-speed civil transport integrated control concept. 
flight-propulsion control system. The topmost level could be the airplane flightpath management system, which would include outer-loop functions.

\section{HIGH-SPEED CIVIL TRANSPORT CONTROL MODES AND POTENTIAL BENEFITS}

Some selected examples of control modes for the various levels of integration shown in Figure 2 will be presented. Estimates of the potential benefits for an HSCT will be made, based on recent experimental and analytical studies.

ENGINE-FLIGHT-CONTROL INTEGRATION Engine fan and compressor stall margins are normally made large enough to accommodate the worst case combination of inlet and engine induced disturbances (for example, an afterburner light during a high sideslip condition). At times when this full level of stall margin is not required, the operating point may be moved closer to the stall line, and additional engine performance (higher thrust, lower SFC, lower temperature) may be achieved. Active real-time control of the stall margins requires large numbers of flight-control system and engine control system parameters.

The system shown in Figure 3 was developed and flight tested on the NASA F-15 HIDEC airplane (4) in the adaptive engine control system (ADECS) program. Engine pressure ratio (EPR) was increased as a function of flight control and engine variables. Thrust increases of 5 to 10 percent were measured. Fuel flow reductions to maintain maximum afterburning thrust were found to be 5 to 15 percent. Constant thrust could be maintained at $20^{\circ}$ to $80^{\circ} \mathrm{F}$ lower fan turbine inlet

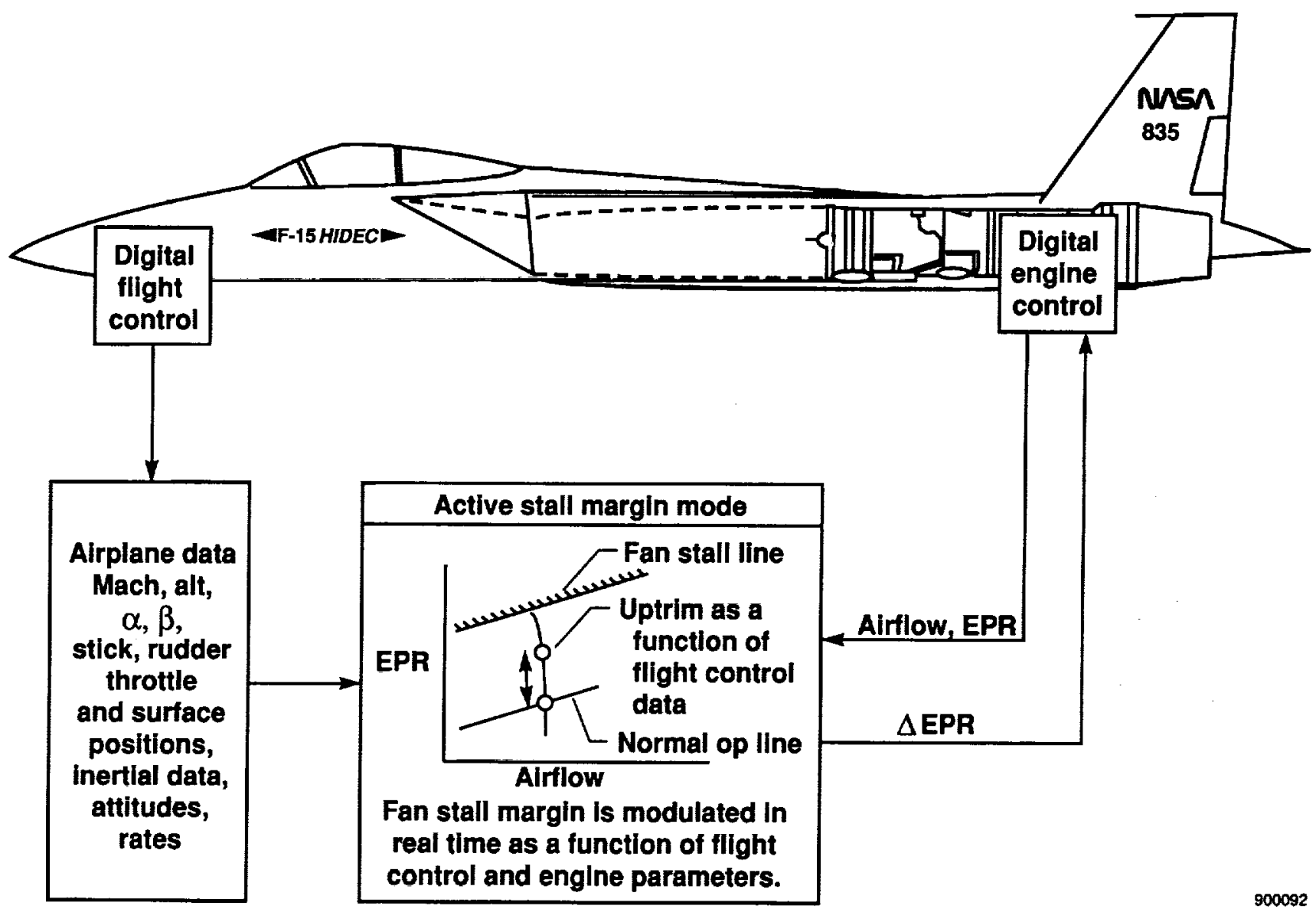

Figure 3. Engine-flight-control integration mode tested on the NASA HIDEC airplane. 
temperatures. For an HSCT, the maneuver requirements will be greatly reduced over the F-15 aircraft, and therefore, there will be smaller benefits for an ADECS mode. However, it is thought that thrust increases of 3 percent may be achieved in normal flight with constant throttle setting.

\section{INLET-ENGINE-FLIGHT-CONTROL} INTEGRATION - There are significant benefits to integrating the inlet control system with the flightcontrol and airdata system. As mentioned previously, a gust sensor on the nose could be used to bias the inlet geometry to a more conservative position. Other flight-control system parameters, such as Mach, angle of attack, and angle of sideslip, also can be used to advantage by the inlet control.

Integration with the engine control is also beneficial. The inlet provides flow to the engine at a given pressure and distortion level. In return, the engine demands a certain airflow which changes with throttle setting. Integrating these control systems allows both inlet and engine operating margins to be reduced, and performance to be improved.

Figure 4 is a conceptual block diagram of an integrated inlet control mode for an HSCT, equipped with a mixed compression inlet. The bypass control mode uses bypass door position to position the terminal shock wave to maximize inlet pressure recovery. The unstart boundary, caused by moving the terminal shock to the throat, is a function of engine alrflow. Without integration, an unstart margin of approximately 5 percent is necessary. This margin is needed either to accommodate a sudden decrease in engine airflow, an external gust, or a combination of both before the control system can react to open the bypass. If airdata and engine data, including airflow information is provided, this margin may be reduced and higher pressure recovery can be obtained.

The compression surface or spike position mode maintains the throat Mach number; efficiency is improved by maintaining throat Mach number close to 1.0 . If throat Mach number gets

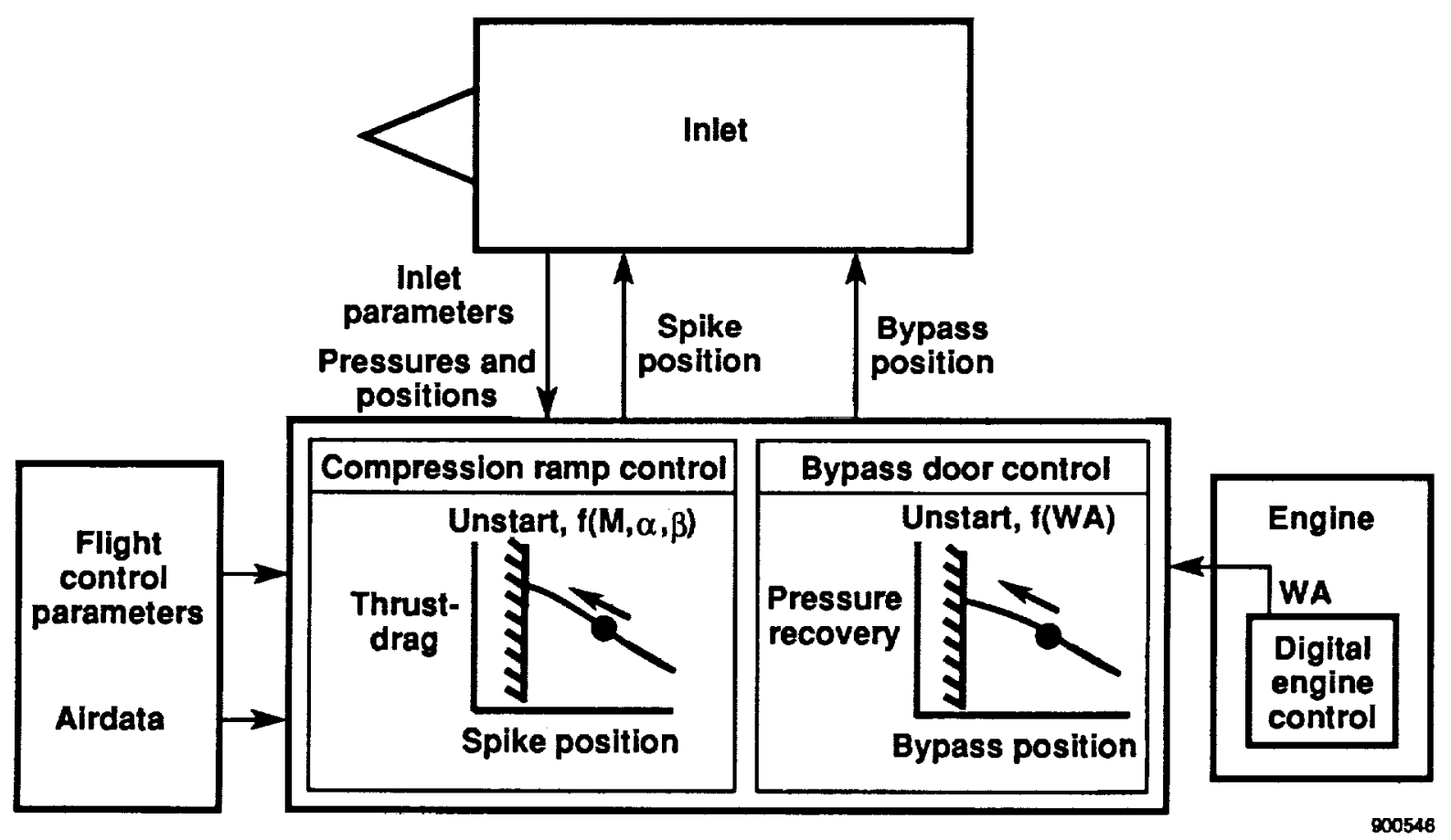

Figure 4. Conceptual integrated inlet-engine-flight-control mode. 
to 1.0, the inlet will unstart. Therefore, a margin must be provided which results in the reduction of the overall thrust minus drag of the inlet. The throat Mach number is a function of Mach, angle of attack, and angle of sideslip. Integration can provide these signals. This integration allows the margin to be reduced and performance to be increased.

An integrated inlet control mode similar to that previously discussed, has been implemented on the F-15 HIDEC airplane (12). The F-15 inlet incorporates a variable capture cowl to minimize external drag, and also has a variable third ramp to control compression and throat Mach number, and a bypass door to modulate throat slot bleed. In the normal F-15 aircraft, these variables are positioned by an independent inlet control system. In the HIDEC inlet integration mode, biases are computed for the variables based on knowledge of engine and airplane conditions. For example, the inlet third ramp is repositioned to move the terminal shock closer to the cowl lip, reducing spillage and increasing pressure recovery. Accurate knowledge of engine airflow from the engine control system is required to prevent supercritical operation, and resulting distortion. The cowl has some pitching moment authority on the F-15 aircraft, and cowl position can be adjusted to mini-

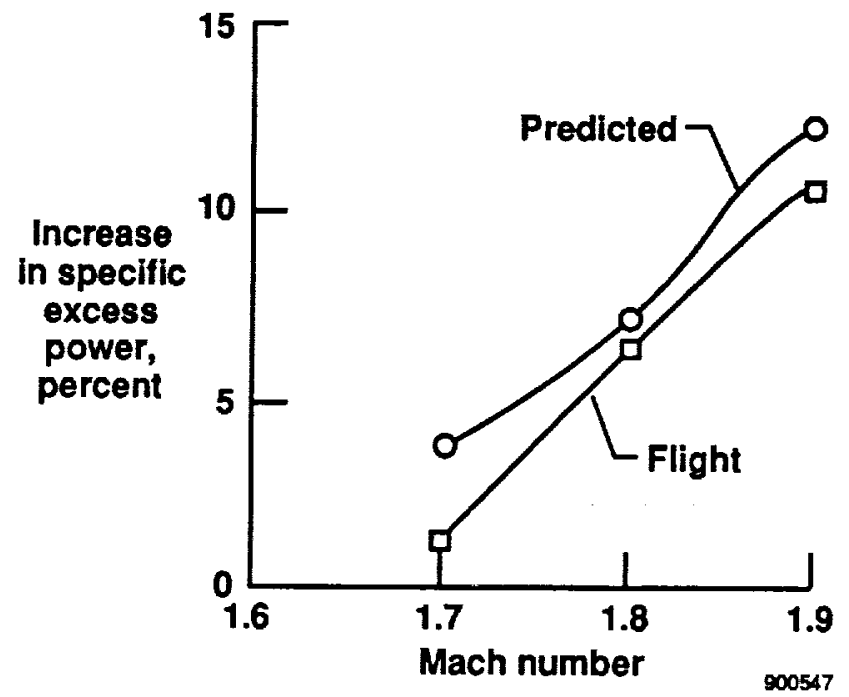

Figure 5. Flight measured results of the F-15 HIDEC integrated inlet control mode. mize horizontal tail trim drag, inlet drag, and inlet recovery. The HIDEC inlet integration control mode was flown and demonstrated increases in excess thrust of as much as 10 percent at a Mach number of 1.9 (Fig. 5). Such a mode could be applied to an HSCT, and would be expected to reduce drag by at least 1 percent.

Mixed Compression Inlet - Control integration has been studied on the inlet of the YF-12 airplane (1). The inlet control was integrated with the flight-control system in the cooperative control program. The SR-71 airplane was able to achieve a range increase in excess of 5 percent using digital integrated control. The HSCT inlet will be more carefully optimized, but integration should still provide 1-to 2-percent better performance.

\section{PERFORMANCE SEEKING CONTROL}

With many variables involved in optimizing the performance of an HSCT, it will be difficult to develop an a priori optimization scheme. Such schemes must assume a nominal system model.

An alternate approach is to perform the optimization onboard the airplane, using the many measured parameters that are already available from the individual control systems (9). Measurements can be used to update models of components such as engines which may vary over time. Figure 6 is a block diagram of a conceptual PSC system on an HSCT. Development of such a system begins with nominal models.

NOMINAL MODELS - Models of the nominal (predicted) propulsion system and trim aerodynamic characteristics are required. The differences between the actual aircraft and the nominal models form the basis for quantifying the differences using an estimator and subsequently determining the model updates described in the following sections.

PARAMETER ESTIMATION - The adaptive capability of the PSC algorithm is provided by an 
estimator. The flight measurements used by the estimator consist of the measured inlet, engine, and aircraft response parameters. These parameters are compared with the predicted nominal operation of the propulsion system and aerodynamic trim control characteristics of the aircraft. The estimator is driven by the difference of these parameters and provides estimates which represent the difference between the predicted and actual propulsion system and aircraft performance.

MODEL UPDATE - The differences estimated in the previous paragraph are used along with the measured variables to update the model of each engine. Inlets, nozzles, and the airframe probably do not change with time, and thus do not need to be updated.

INTEGRATED MODEL - The individual models of the inlet, engine, nozzle, flight-control system, and airplane aerodynamics are then integrated so that the optimization process can solve the overall integrated problem. Unmeasured parameters, such as stall margins and thrust are calculated in the models. Although the basic models are linear, nonlinear effects can be included as auxiliary equations.

OPTIMIZATION - Optimization is then carried out on the combined system, including the engine, inlet, and aerodynamic trim characteristics for the desired performance parameter, using an optimization algorithm. Candidate performance objectives could be maximum thrust, minimum fuel, maximum engine life, and maximum thrust at constant temperature. Outputs of the optimization are engine, inlet, nozzle, CG, and aerodynamic flight-control parameters. These parameters are computed as trims to the current control inputs and as such are summed with the current control positions.

A preliminary flight evaluation of the PSC concept is currently in the development and validation process on the NASA F-15 HIDEC aircraft.

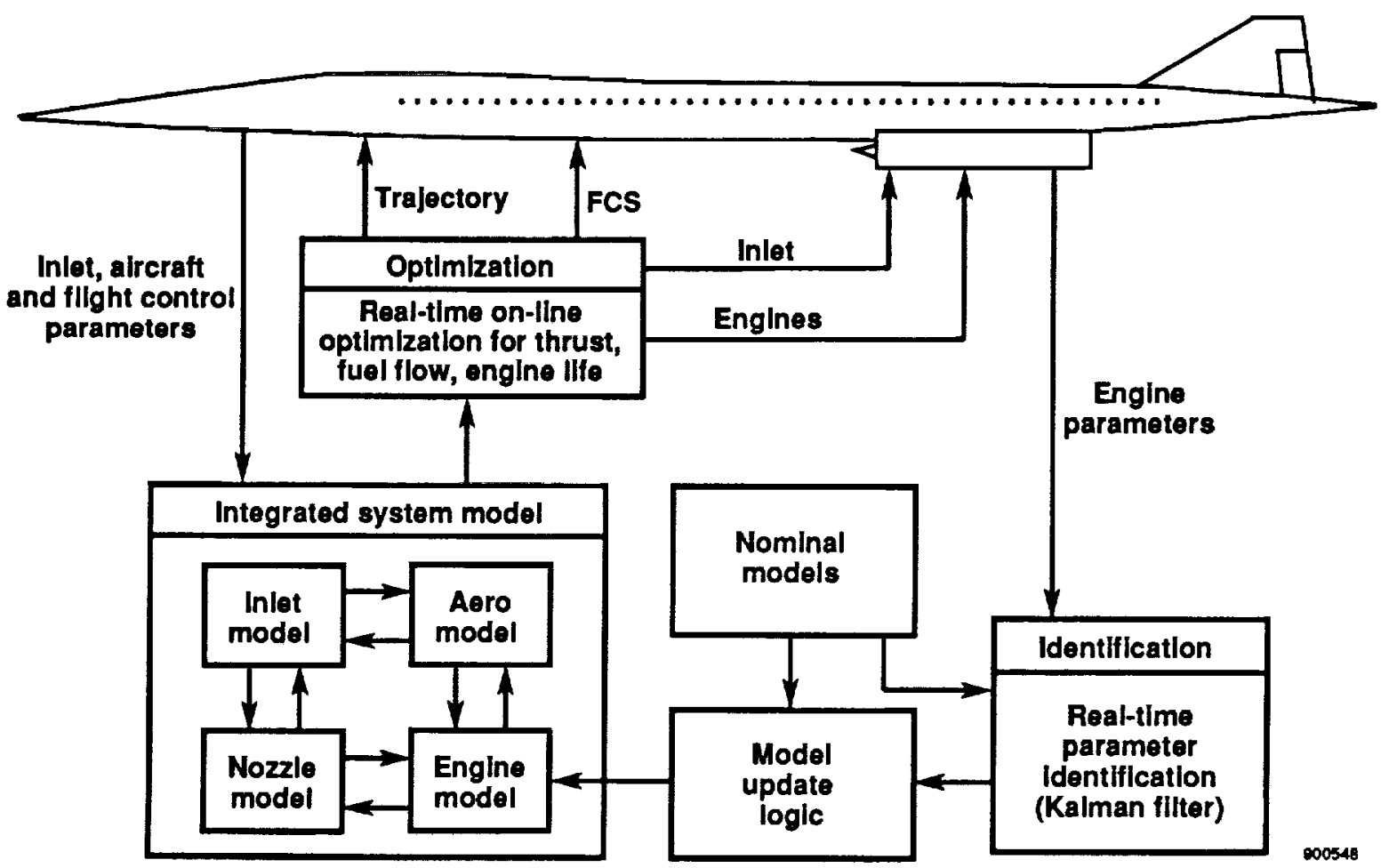

Figure 6. Conceptual HSCT performance-seeking control block diagram. 
The algorithm, similar to that previously described, is an onboard real-time adaptive optimization of engine, inlet, and nozzle parameters. An example of the optimization process at a Mach number of 1.9 at partial afterburning is shown in Figure 7. The objective is to minimize fuel flow to provide the required thrust for level flight. Predictions obtained from a full nonlinear PSC simulation show that engine, inlet-horizontal tail, and nozzle parameters are all changed as a result of the mode "seeking" the optimum. After approx- imately 80 passes through the optimization routine, the overall result is a 12-percent reduction in fuel flow. In this case, as shown in the inset, the engine net thrust is decreased, the nozzle drag is increased and the inlet drag is decreased to hold constant net propulsive force from the propulsion system. These optimization benefits obviously would not be available in a system where the optimization was being performed on the engine, inlet, nozzle, and horizontal tail independently.

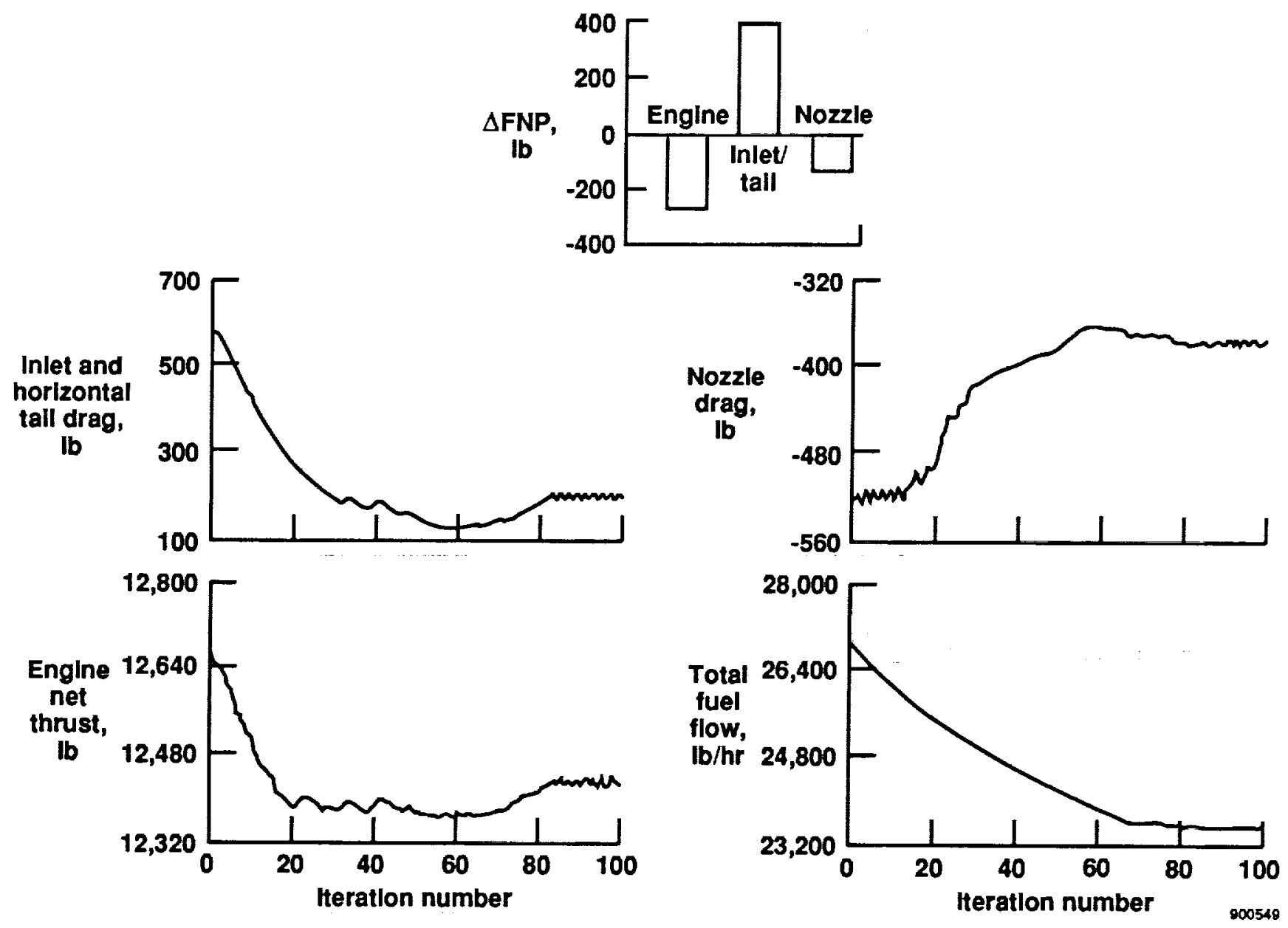

Figure 7. Predicted performance-seeking control optimization for minimum fuel flow at constant thrust, F-15 HIDEC airplane, Mach 1.9, 45,000 ft, power level angle = 120 . 
Figure 8 shows the fuel flow decrease at Mach 1.6 and 2.0 over a range of partial afterburning power settings. Reductions range from 2 to 12 percent. For the HSCT, gains due to PSC will be smaller, since the HSCT will not have the maneuver requirements of an F-15, and can be better optimized. However, it is estimated that a 3-percent reduction in SFC should be obtainable.

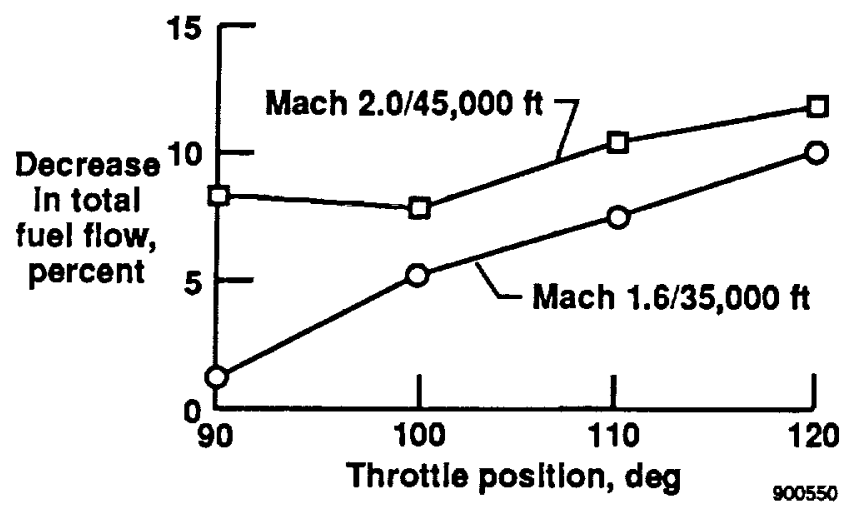

Figure 8. Predicted PSC fuel flow reductions for partial afterburning power settings, F-15 airplane.

The PSC algorithm may also be optimized for maximum thrust. For the F-15 airplane, thrust increases of 10 to 15 percent have been predicted $(1,9)$. For the HSCT, gains are expected to be approximately 3 to 5 percent.

For the HSCT, PSC will employ stronger integration with the FCS and aerodynamics. For example, the individual inlet bleed and bypass forces and moments may be used to minimize longitudinal control surface deflections. Individual thrust levels of the propulsion systems may be adjusted to minimize lateral control deflections. The CG may be moved aft farther than normally practical by having propulsion system moments available to augment longitudinal stability quickly, if required.

\section{EMERGENCY CONTROL MODES}

Integration between the propulsion and flight control systems is also valuable in emergency situations.
ENGINE FAILURE AT TAKEOFF ROTATION An application for integration is the loss of an engine at takeoff rotation. Current regulations require that the takeoff be completed without throttle motion. The asymmetric thrust caused by uncompensated loss of an outboard engine may size the vertical tail. An integrated control mode could reduce the thrust on the opposite outboard engine, increase thrust on the inboard engines, retract the noise suppressors, and allow the tail size to be reduced by approximately 25 percent. Of course, there may then be other sizing constraints on the tail, but if not, this advantage may be used to reduce the HSCT weight and drag.

RAPID DESCENT MODE - An HSCT may have a requirement for a rapid descent mode, due to a sudden loss of cabin pressurization. Slowing down from the cruise speed and altitude of 55,000 to $60,000 \mathrm{ft}$ to subsonic speed at an altitude of $20,000 \mathrm{ft}$ in a short time will be difficult. At supersonic speeds, engine thrust is normally maintained at or above intermediate power to avoid inlet buzz. (Inlet buzz is a potentially violent pressure oscillation that occurs when the airflow of an inlet operating at supersonic speeds is reduced too far). An integrated control mode is needed for this case in which net propulsive force needs to be minimized. The propulsion system thrust needs to be reduced to the lowest possible level, yet strong inlet buzz must either be avoided, or the inlet strengthened to withstand buzz. This means that the engine airflow will have to be kept up well above idle values. If the HSCT has mixed compression inlets, they can be operated either unstarted or in a very low performance mode until the inlet starting Mach number is reached. 
The control mode shown in Figure 9 integrates the inlet, engine, and nozzle to produce minimum thrust consistent with engine, inlet, and nozzle operating limits. The inlet operation reconfigures the ramps and bypass for minimum pressure recovery and airflow capability, in contrast to the normal mode where the opposite is true.

The engine airflow is reduced to the inlet buzz limit, and the nozzle throat area $(A 8)$ is opened as far as possible to reduce thrust. Then, the secondary nozzle $(A 9)$ is positioned to create as much drag as possible. A high response sensor at the engine face could be used to reduce airflow until very light buzz is sensed, then maintain this condition. Integration with the flight-control system is also required to permit the steepest descent consistent with the propulsion system limits. It is estimated that with this integrated control mode to prevent buzz, the inlet weight could be reduced by 2 percent.

\section{HIGH SPEED CIVIL TRANSPORT DESIGN SYNTHESIS PROGRAM}

The aircraft synthesis program (ACSYNT) $(10,11)$ was used to determine the impact of integrated controls technology on the HSCT. This design code takes as inputs the required passenger volume and range, and basic aerodynamics and propulsion. It then iteratively computes a design with the proper structure and fuel volume that will meet minimum performance requirements for takeoff and landing distance, transonic acceleration margin, and time to climb. The generic HSCT design with the configuration from Figure 1 was developed using 1995 technology turbine bypass

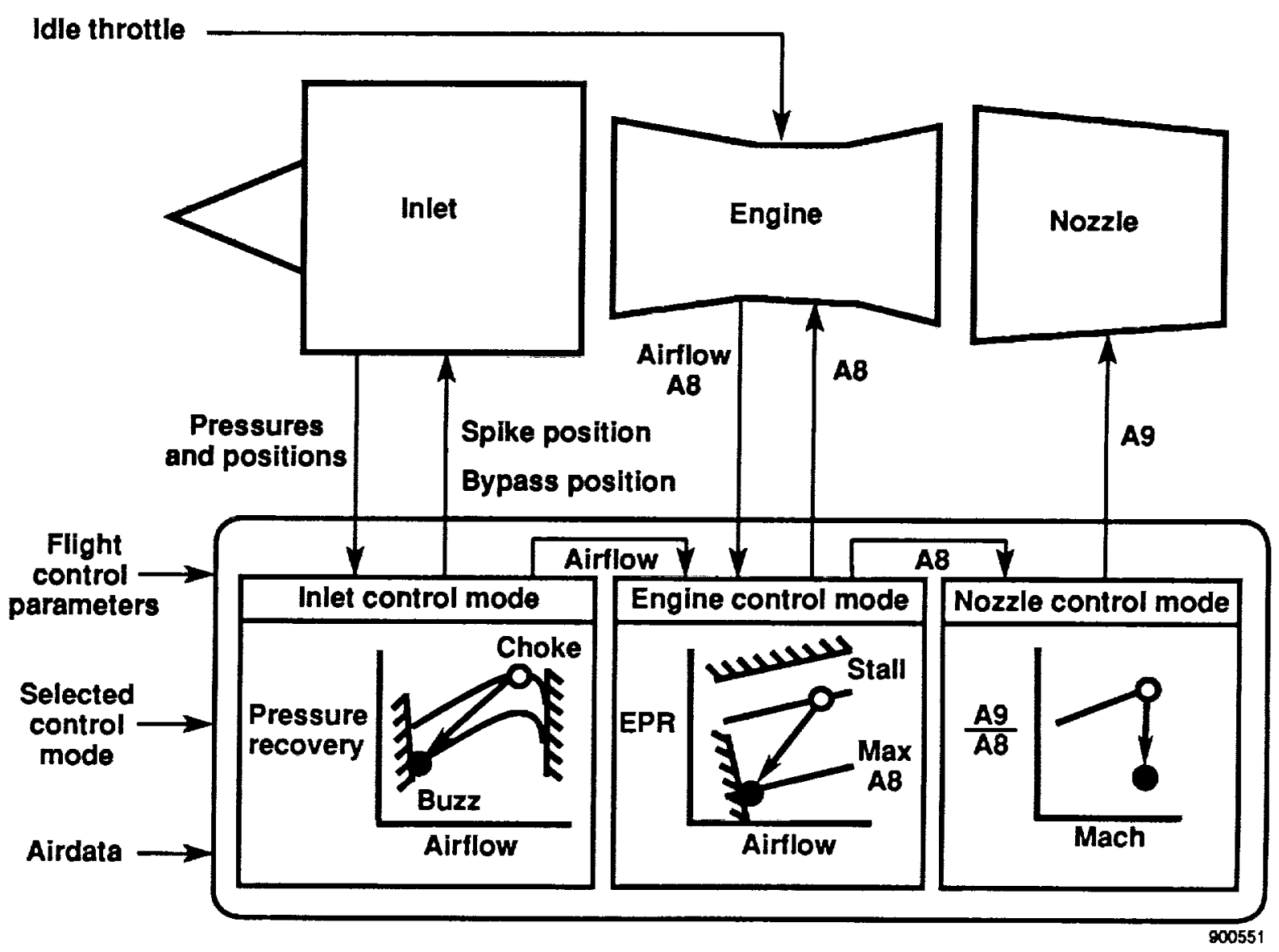

Figure 9. Conceptual integrated engine-inlet-nozzle control mode for minimum thrust. 
Effect of integrated control technologies on takeoff gross weight.

\begin{tabular}{|c|c|c|c|c|}
\hline Technology & $\begin{array}{l}\text { Result of Technology } \\
\text { Improvement }\end{array}$ & $\begin{array}{l}\text { Percent } \\
\text { improvement }\end{array}$ & $\begin{array}{l}\Delta \text { TOGW } \\
\text { percent }\end{array}$ & $\begin{array}{l}\text { Parameter } \\
\text { sensitivity }\end{array}$ \\
\hline Integrated engine/flt controls & Reduction of engine weight & 3.00 & 0.42 & 0.141 \\
\hline Integrated engine/flt controls & Nozzle weight reduction & 1.00 & 0.09 & 0.087 \\
\hline Integr inlet/engine/flt control & $\begin{array}{l}\text { Lower inlet drag, } \\
\% \text { reduction of aircraft drag }\end{array}$ & 1.00 & 0.22 & 0.216 \\
\hline Integr inlet/engine/flt control & $\begin{array}{l}\text { Higher inlet recovery } \\
\text { and maximum thrust }\end{array}$ & 1.00 & 0.36 & 0.364 \\
\hline Performance-seeking control & Improvement in cruise SFC & 3.00 & 2.44 & 0.812 \\
\hline Engine loss at takeoff rotation & Vertical tail size reduction & 25.00 & 1.16 & 0.046 \\
\hline Emerg minimum thrust mode & Inlet weight reduction & 2.00 & 0.09 & 0.047 \\
\hline \multirow[t]{2}{*}{ Integrated control architecture } & $\begin{array}{l}20 \% \text { FCS weight reduction } \\
\text { (.5\% of empty wt.) }\end{array}$ & 20.00 & 0.55 & 0.028 \\
\hline & Combined impact & 5.07 & & \\
\hline
\end{tabular}

engines. It carries 250 passengers 5000 nautical miles at Mach 2.4 with normal fuel reserves. The ACSYNT computes sensitivities caused by technology changes. For small changes, these sensitivity factors are linear, so the effects of different technology impacts than those estimated here could also be assessed.

\section{IMPACT OF INTEGRATION ON THE HIGH SPEED CIVIL TRANSPORT TAKEOFF GROSS WEIGHT}

The HSCT will experience significant benefits from integration and onboard optimization. Based on some of the reference results, including flight results of the YF-12 and F-15 HIDEC programs, estimates of performance improvements and weight reductions have been made, and are shown in the above table. For example, current studies show that the HSCT engines may be sized for time to climb. The use of an integrated engineflight-control mode should enable the engine to be uptrimmed at these benign conditions, reducing the required engine weight by 3 percent. The smaller engine will permit the nozzle to be smaller also, with a 1-percent reduction in nozzle weight. Inlet integration could also reduce inlet drag by 1 percent of total drag, and increase inlet recov- ery by 1 percent. Use of PSC concepts should reduce the cruise SFC by approximately 3 percent. The inlet weight may be reduced by 2 percent with the use of the minimum thrust mode. The control integration architecture studies of reference 6 showed that integration could reduce the weight of the control system by 20 percent; approximately one-half percent of overall airplane empty weight.

The impact of each of the technology improvements was determined by integrating them into the generic HSCT design, using ACSYNT. Figure 10 shows the reduction in TOGW for each of the items shown in the table. The table also shows the sensitivity factor (the change in TOGW divided by the change in the parameter) of each. The largest effect is seen to be the result of SFC improvements; drag reductions are less significant, and weight reductions have the least impact. The overall effect is an approximate 5 -percent reduction in TOGW, a significant reduction.

The sensitivity factors will be useful when more detailed studies provide better estimates of the benefits of integration. These factors also allow prioritization of research, emphasizing fuel savings as the highest priority. In the HSCT actual 
design, each of the integration concepts will need to be studied, its benefits determined, and then a decision made as to whether the concept can buy its way into the design.

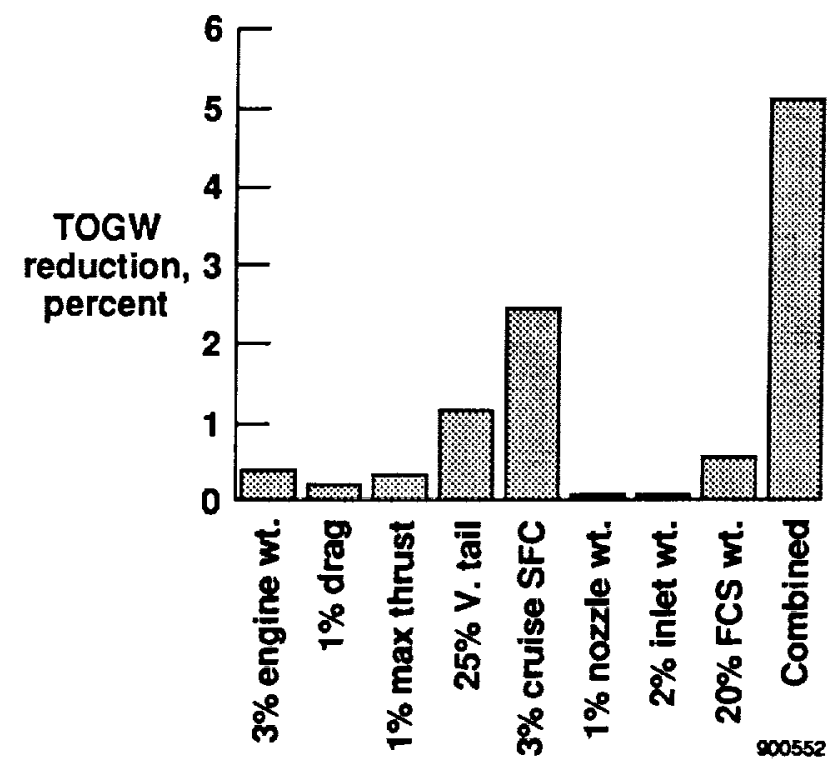

Figure 10. Effect of integrated control technology improvements on generic HSCT TOGW.

\section{CONCLUDING REMARKS}

A conceptual look at propulsion-flight-control integration for a high speed civil transport has been made. Potentially useful control modes have been discussed, and related to integrated control modes tested on the NASA YF-12 and F-15 flight-research programs. The potential benefits have been estimated and used to assess their impact on the takeoff gross weight for the high-speed civil transport design mission. A 5percent reduction in takeoff gross weight is estimated, and shows the value of integrated controls. The largest benefits result from fuel savings, less for drag reduction, and least for weight reduction.

\section{REFERENCES}

1. Burcham, Jr., Frank W., Glenn B. Gilyard, and Lawrence P. Myers, "Propulsion SystemFlight Control Integration-Flight Evaluation and Technology Transition," AIAA Paper 902280, July 1990. See also NASA TM-4207. 1990.

2. Gilyard, Glenn B. and John J. Burken, Development and Flight Test Results of an Autothrottle Control System at Mach 3 Cruise, NASA TP-1621, 1980.

3. Powers, Bruce G., Phugoid Characteristics of YF-12 Airplane With Variable-Geometry Inlets Obtained in Flight Tests at a Mach Number of 2.9, NASA TP-1107, 1977.

4. Myers, Lawrence P. and Kevin R. Walsh, Performance Improvements of an F-15 Airplane With an Integrated Engine-Flight Control System, NASA TM-100431, 1988.

5. Smith, Kenneth L., W. Bernie Kerr, Gary L. Hartman, and Charles Skira, "Aircraft Control Integration-Methodology and Performance Impact," AIAA Paper 85-1424, July 1985.

6. Bangert, L.H., K.R. Henke, R.J. Grommes, and W.B. Kerr, "Integrated Flight/Propulsion Control System Architectures for a High Speed Aircraft," AIAA Paper 83-2563, Oct. 1983.

7. Blair, J.D., and C.M. Carlin, "Integrated Control System Concept for High-Speed Aircraft," AIAA Paper 83-2564, Oct. 1983.

8. Berg, D.F., J.A. Swan, S. Ahdibatlar, P.D. Shaw, and E.J. Tich, "Performance Seeking Control; Volume I: Final Report,"-AFWAL-TR-88-2067, Oct. 1989. 
9. Smith, R.H., J.D. Chisolm, and J.F. Stewart, "Optimizing Aircraft Performance with Adaptive, Integrated Flight/Propulsion Control," ASME Paper 90-GT-252, June 1990.

10. Gregory, T.J., "Computerized Preliminary Design at the Early Stages of Vehicle Definition," Presented at the AGARD 43rd Flight Mechanics Panel Symposium on Aircraft Design Integration and Optimization, TMX-62303, Sept. 1973.
11. Wampler, S.G., A. Myklebust, A. Jayaram, and P. Gelhausen, "Improving Aircraft Conceptual Design - A PHIGS Interactive Interface for ACSYNT," AIAA Paper 88-4481, Sept. 1988.

12. Chisholm, J.D., S.G. Nobbs, and J.F. Stewart, "Development of the HIDEC Inlet Integration Mode," paper presented at the ASME Gas Turbine Conference, July 1989. 


\begin{tabular}{|c|c|c|}
\hline \multicolumn{3}{|c|}{ Report Documentation Page } \\
\hline $\begin{array}{l}\text { 1. Report No. } \\
\text { NASA TM-101728 }\end{array}$ & 2. Government Accession No. & 3. Recipient's Catalog No. \\
\hline \multirow{2}{*}{\multicolumn{2}{|c|}{$\begin{array}{l}\text { 4. Title and Subtitle } \\
\text { Integrated Flight-Propulsion Control Concepts for Supersonic } \\
\text { Transport Airplanes }\end{array}$}} & $\begin{array}{l}\text { 5. Report Date } \\
\text { November } 1990\end{array}$ \\
\hline & & 6. Performing Organization Code \\
\hline \multirow{2}{*}{\multicolumn{2}{|c|}{$\begin{array}{l}\text { 7. Author(s) } \\
\text { Frank W. Burcham, Jr., Glenn B. Gilyard, and Paul A. Gelhausen }\end{array}$}} & $\begin{array}{l}\text { 8. Performing Organization Report No. } \\
\text { H-1673 }\end{array}$ \\
\hline & & $\begin{array}{l}\text { 10. Work Unit No. } \\
\text { RTOP 533-02 }\end{array}$ \\
\hline \multirow{2}{*}{\multicolumn{2}{|c|}{$\begin{array}{l}\text { 9. Pertorming Organization Name and Address } \\
\text { NASA Ames Research Center } \\
\text { Dryden Flight Research Facility } \\
\text { P.O. Box 273, Edwards, CA } 93523-0273\end{array}$}} & 11. Contract or Grant No. \\
\hline & & 13. Type of Report and Period Covered \\
\hline \multirow{2}{*}{\multicolumn{2}{|c|}{$\begin{array}{l}\text { 12. Sponsoring Agency Name and Address } \\
\text { National Aeronautics and Space Administration } \\
\text { Washington, DC } 20546-0001\end{array}$}} & Technical Memorandum \\
\hline & & 14. Sponsoring Agency Code \\
\hline
\end{tabular}

16. Abstract

Integration of propulsion and flight-control systems will provide significant performance improvements for supersonic transport airplanes. Increased engine thrust and reduced fuel consumption can be obtained by controlling engine stall margin as a function of flight and engine operating conditions. Improved inlet pressure recovery and decreased inlet drag can result from inlet control system integration. Using propulsion system forces and moments to augment the flight-control system and airplane stability can reduce the flight-control surface and tail size, weight, and drag. Special control modes may also be desirable for minimizing community noise and for emergency procedures. The overall impact of integrated controls on the takeoff gross weight for a generic high speed civil transport is presented.

\begin{tabular}{|l|l|l|l|}
\hline $\begin{array}{l}\text { 17. Key Words (Suggested by Author(s)) } \\
\begin{array}{l}\text { F-15, HSCT, Integrated control, Performance } \\
\text { seeking control, Integrated control }\end{array}\end{array}$ & $\begin{array}{l}\text { 18. Distribution Statement } \\
\text { Unclassified-Unlimited }\end{array}$ \\
Subject category - 08 \\
$\begin{array}{l}\text { 19. Security Classif. (of this report) } \\
\text { Unclassified }\end{array}$ & $\begin{array}{l}\text { 20. Security Classif. (of this page) } \\
\text { Unclassified }\end{array}$ & $\begin{array}{c}\text { 21. No. of Pages } \\
15\end{array}$ & 22. Price \\
A02
\end{tabular}

